Anasthasia, Sinta Paramita: Pengaruh Crisis responsibility Terhadap Post-Crisis Reputation pada Maskapai Garuda Indonesia

\title{
Pengaruh Crisis Responsibility Terhadap Post-Crisis Reputation pada Maskapai Garuda Indonesia
}

\author{
Anasthasia, Sinta Paramita \\ Thasia.alberta@gmail.com, Sintap@fikom.untar.ac.id
}

Fakultas Ilmu Komunikasi Tarumanagara

\begin{abstract}
This research was conducted by considering the problems that occur in Garuda Indonesia. Cite the problem of food menus that use writing in Indonesia. Garuda Indonesia's response to the case discussed below. Garuda Indonesia losses. The purpose of this study was to determine the relationship between crisis responsibility and post-crisis reputation obtained by Garuda Indonesia and to determine the relationship between crisis responsibility and post-crisis reputation by Garuda Indonesia. This study uses a quantitative method with a questionnaire as a method of collecting data distributed to Garuda Indonesia passengers discussing Garuda Indonesia about food menu updates by handwriting. The results showed that the crisis had a significant responsibility for post-crisis reputation in Garuda Indonesia. This happens because it occurs during a transition period, an action or response from the parties concerned becomes very fundamental to the image held after the case is finished. Public relations has a very important role in responding to debates. The mistake made by Garuda Indonesia by prohibiting visitors from taking pictures on the plane made Garuda Indonesia's post-crisis reputation also increase.
\end{abstract}

Keyowrds: Crisis Responsibility, Post-Crisis Reputation, Public Relations

\begin{abstract}
Abstrak
Penelitian ini dijalankan didasari atas permasalahan pada maskapai Garuda Indonesia terutama mengenai penulisan menu makanan yang menggunakan tulisan kertas serta respon Garuda Indonesia terhadap kasus tersebut yang dianggap kurang baik karena melarang seluruh penumpang maskapai Garuda Indonesia untuk mendokumentasikan gambar di dalam kabin Garuda Indonesia dan diduga hal tersebut dapat menurunkan reputasi Garuda Indonesia pasca krisis tersebut. Tujuan dari penelitian ini adalah untuk mengetahui untuk mengetahui hubungan crisis responsibilit dengan post-crisis reputation maskapai Garuda Indonesia dan untuk mengetahui seberapa besar pengaruh crisis responsibility terhadap postcrisis reputation maskapai Garuda Indonesia. Penelitian ini menggunakan metode kuantitatif dengan kuesioner sebagai metode pengumpulan data yang disebarkan kepada penumpang Garuda Indonesia yang mengetahui permasalahan Garuda Indonesia mengenai penulisan menu makanan dengan tulisan tangan. Hasil penelitian menunjukkan bahwa crisis responsibility berpengaruh signifikan terhadap post-crisis reputation pada Garuda Indonesia. Hal ini terjadi karena saat sebuah maskapai penerbangan mengalami masalah, sebuah tindakan atau respons dari pihak maskapai tersebut menjadi sangat fundamental bagi citra maskapai itu sendiri setelah kasus tersebut selesai. Public relations memiliki peranan yang sangat penting dalam menyikapi permasalahan. Kesalahan yang dilakukan pihak Garuda Indonesia dengan melarang seluruh pengunjung berfoto di dalam pesawat membuat postcrisis reputation Garuda Indonesia juga menurun.
\end{abstract}

Kata Kunci: Crisis responsibility, Post-Crisis Reputation, Public Relations 


\section{Pendahuluan}

Reputasi perusahaan atau corporate reputation adalah total penilaian dari atribut-atribut stakeholder pada perusahaan, berdasarkan pada persepsi-persepsi mereka dan interpretasi-interpretasi pada citra perusahaan yang dikomunikasikan secara terus menerus Krisprimandoyo (2014). Dari definisi tersebut, tentunya reputasi harus dijaga dengan baik oleh perusahaan-perusahaan penerbangan di Indonesia, namun tidak sedikit juga permasalahan-permasalahan yang menimpa maskapai penerbangan di Indonesia yang dapat menjatuhkan reputasi perusahaan.

Majunya perkembangan zaman dan adanya perkembangan teknologi menyebabkan manusia menjadi mudah untuk melakukan komunikasi. Perkembangan zaman ini tentunya membawa dampak positif dan dampak negatif. Dampak positifnya manusia dapat menerima informasi dan menyampaikan informasi dengan mudah dan cepat. Dampak negatif dari adanya perkembangan zaman ini, muncul tantangantantangan baru bagi seorang PR.

Di Indonesia sendiri, sangat banyak kasus yang berkaitan dengan reputasi perusahaan penerbangan, dan yang saat ini sempat bermasalah adalah permasalahan pada maskapai Garuda Indonesia yang memberikan menu makanan dalam bentuk tulisan tangan terhadap tamunya yang merupakan salah satu public figure terkemuka di Indonesia yaitu Rius Vernandes. Kasus ini memosisikan maskapai Garuda Indonesia dalam keadaan crisis, terutama crisis kepercayaan.

Namun, permasalahan tersebut tidak selesai sampai disana, dikarenakan, setelah kasus tersebut, pihak Garuda Indonesia dengan public relations-nya menjalankan crisis responsibility yang dianggap kurang tepat. Crisis responsibility menurut Coombs and Holladay, (2002) adalah sebuah tanggapan atas permasalahan yang menghadapi sebuah perusahaan. Penerapan crisis responsibility menjadi sebuah hal yang sangat fundamental karena dapat mempengaruhi hal-hal yang terjadi setelah krisis itu sendiri terjadi. Dalam kasus Garuda Indonesia sendiri, Crisis responsibility yang dijalankan dianggap kurang tepat karena melarang penumpang untuk merekam atau mengabadikan seluruh kegiatan selama penerbangan

Kedua tanggapan dari maskapai Garuda Indonesia yang diharapkan dapat memperbaiki reputasi maskapai Garuda Indonesia ini malah berbalik mendapatkan tanggapan negatif dari masyarakat Indonesia, dan semakin menjatuhkan reputasi Garuda Indonesia. Permasalahan inilah yang akan digali dalam penelitian ini. Hal ini dibuktikan dari tanggapan beberapa public figure seperti dari pihak @globaltraveler.tv, @iamrofi_ sebagai pelanggan setia Garuda Indonesia, @adrianmaulana dan masih banyak lagi influencer dan public figure yang juga menyayangkan dan menilai keputusan tersebut adalah keputusan yang salah. Tentunya tanggapan tersebut dapat membentuk reputasi buruk dari masyarakat terhadap Garuda Indonesia paska permasalahan menu makanan yang ditulis tangan tersebut. 
Anasthasia, Sinta Paramita: Pengaruh Crisis responsibility Terhadap Post-Crisis Reputation pada Maskapai Garuda Indonesia

\section{Metode Penelitian}

Metode penelitian yang digunakan dalam penelitian ini adalah metode eksperimen dengan pendekatan studi kasus. Menurut Sugiyono (2018) metode eksperimen adalah metode penelitian kuantitatif yang digunakan untuk mengetahui pengaruh variabel independen terhadap variabel dependen dalam kondisi yang terkendalikan. Pendekatan metode yang digunakan adalah metode survei. Pendekatan survei adalah pendekatan dimana penelitian kuantitatif menggunakan kuesioner dalam pengumpulan datanya. Dalam penelitian ini, dikarenakan kuesioner yang digunakan sebagai alat bantu, maka penelitian kuantitatif ini masuk dalam pendekatan survei.

Pendekatan penelitian yang digunakan dalam penelitian ini adalah pendekatan asosiatif dengan rentang waktu cross sectional. Pendekatan penelitian asosiatif menurut Sugiyono (2018:15) adalah pendekatan yang mengacu pada hubungan sebab akibat antara dua variabel yang saling berkaitan. Penelitian ini menggunakan pendekatan asosiatif karena penelitian ini mencoba meneliti bagaimana variabel bebas dapat menyebabkan perubahan pada variabel terikat.

Selanjutnya rentang waktu cross sectional menurut Sugiyono (2018) adalah rentang waktu dimana penelitian ini hanya dijalankan satu kali. Artinya, penelitian ini bukanlah penelitian eksperimental yang dilakukan beberapa kali hingga mencapai sebuah tujuan tertentu, namun terbatas hanya memberikan hasil analisa dan rekomendasi dari hasil statistika yang telah dilakukan. Penelitian ini menggunakan rentang waktu cross sectional karena penyebaran kuesioner hanya dilakukan satu kali, dan hasil pemaparan data juga hanya dilakukan satu kali, tanpa dianalisis kembali implementasi atau saran dari penelitian ini.

Dalam penelitian ini, metode pengambilan sampel yang digunakan adalah non-probability sampling dengan pendekatan purposive sampling. Metode nonprobability sampling adalah metode pengambilan sampel dimana tidak semua populasi memiliki kesempatan yang sama untuk menjadi sampel. Sedangkan pendekatan purposive sampling adalah pendekatan penelitian dimana terdapat kriteria khusus dalam pengambilan sampel. Dalam penelitian ini, yang menjadi kriteria dalam penelitian adalah:

1. Pernah menggunakan maskapai Garuda Indonesia

2. Mengetahui permasalahan yang dialami oleh Garuda Indonesia menyangkut menu makanan yang ditulis tangan

3. Mengetahui cara Garuda Indonesia menanggapi berita tersebut. 


\section{Hasil Penemuan dan Diskusi}

Berikut adalah hasil temuan dan diskusi dari penelitian ini: 曲

Model Summary

\begin{tabular}{|l|r|r|r|c|}
\hline Model & $\mathrm{R}$ & $\mathrm{R}$ Square & \multicolumn{1}{c|}{$\begin{array}{c}\text { Adjusted } \mathrm{R} \\
\text { Square }\end{array}$} & $\begin{array}{l}\text { Std. Error of the } \\
\text { Estimate }\end{array}$ \\
\hline 1 & $.741^{\mathrm{a}}$ & .548 & .544 & .38602 \\
\hline
\end{tabular}

a. Predictors: (Constant), CRISIS_RESPONSE

b. Dependent Variable: REPUTATION

Sumber: Data Primer yang Diolah

Menurut Imam Ghozali dalam Kartika (2009:10), Koefisien determinasi $\left(\mathrm{R}^{2}\right)$ pada intinya mengukur seberapa jauh kemampuan model dalam menjelaskan variasi variabel independen. Berdasarkan pada tabel tersebut diketahui bahwa $\mathrm{R}$ Square sebesar 0,548 yang artinya variabel independen (crisis-responsibility) dapat menjelaskan variabel dependen (post-crisis reputation) sebesar $54.8 \%$ dan sisanya sebesar $45.2 \%$ dijelaskan oleh variabel lainnya.

\begin{tabular}{|c|c|c|c|c|c|c|c|c|}
\hline \multicolumn{9}{|c|}{ Coefficients $^{\mathrm{a}}$} \\
\hline \multirow[t]{2}{*}{ Model } & \multicolumn{2}{|c|}{$\begin{array}{l}\text { Unstandardized } \\
\text { Coefficients }\end{array}$} & \multirow{2}{*}{\begin{tabular}{|c|}
$\begin{array}{c}\text { Standardized } \\
\text { Coefficients }\end{array}$ \\
Beta \\
\end{tabular}} & \multirow[t]{2}{*}{$\mathrm{t}$} & \multirow[t]{2}{*}{ Sig. } & \multicolumn{3}{|c|}{ Correlations } \\
\hline & B & $\begin{array}{l}\text { Std. } \\
\text { Error }\end{array}$ & & & & $\begin{array}{l}\text { Zero- } \\
\text { order }\end{array}$ & Partial & Part \\
\hline (Constant) & 1.119 & .223 & & 5.009 & .000 & & & \\
\hline CRISIS_RESPONSE & .694 & .061 & .741 & 11.452 & .000 & .741 & .741 & .741 \\
\hline
\end{tabular}

Sumber: Data Primer yang Diolah

Uji $\mathrm{T}$ digunakan untuk menguji pengaruh dari masing-masing variabel independen terhadap variabel dependen (Sugiyono, 2017:184). Setelah menghitung menggunakan SPSS, dapat dilihat nilai Sig. Variabel crisis responsibility sebesar 0.000 yang berarti apabila sig < 0,05 maka Ha diterima. Berarti hasil tersebut dapat disimpulkan bahwa hipotesis yang menyatakan bahwa crisis responsibility berpengaruh signifikan terhadap post-crisis reputation diterima

Dari hasil analisis statistika yang dijalankan, ditemukan bahwa nilai konstanta sebesar 1.119 mengandung arti bahwa nilai konsisten variabel post-crisis reputation adalah sebesar 1.119. Nilai koefisien regresi untuk variabel crisis responsibility adalah sebesar 0.694, ini menunjukkan bahwa crisis responsibility memiliki pengaruh terhadap post-crisis reputation. Hal ini memiliki arti bahwa setiap 
kenaikan crisis responsibility sebanyak 1 satuan maka post-crisis reputation akan bertambah sebesar 0.694 .

Berdasarkan hasil uji T (Parsial), ditemukan bahwa nilai Sig. Variabel crisis responsibility sebesar 0.000 yang berarti apabila sig $<0,05$ maka Ha diterima. Berarti hasil tersebut dapat disimpulkan bahwa hipotesis yang menyatakan bahwa crisis responsibility berpengaruh signifikan terhadap post-crisis reputation diterima. Hal ini sejalan dengan penelitian sebelumnya yang dijalankan oleh Gunawan et al, (2015) dimana Hasil penelitian menunjukkan bahwa memang krisis dapat berpengaruh terhadap reputasi perusahaan, namun manajemen krisis adalah faktor yang lebih penting untuk menjaga reputasi perusahaan.

Penelitian ini juga sesuai dengan teori public relations dimana menurut Jethwaney \& Sarkar dalam Onyango (2018), dijelaskan bahwa tugas dari public relations salah satunya adalah memahami nilai-nilai inti dan kompetensi organisasi. Oleh karena itu, kesalahan dalam menanggapi krisis sangat besar pengaruhnya terhadap kompetensi organisasi. Hal inilah yang membuat Public Relations harus berhati-hati dalam mengambil keputusan dalam menyikapi sebuah krisis.

\section{Simpulan}

Berdasarkan hasil pembahasan diatas, diketahui bahwa variabel crisis responsibility berpengaruh signifikan terhadap post-crisis reputation pada Garuda Indonesia. Hal ini terjadi karena saat sebuah maskapai penerbangan mengalami masalah, sebuah tindakan atau response dari pihak maskapai tersebut menjadi sangat fundamental bagi citra maskapai itu sendiri setelah kasus tersebut selesai. Public relations memiliki peranan yang sangat penting dalam menyikapi permasalahan. Kesalahan yang dilakukan pihak Garuda Indonesia dengan melarang seluruh pengunjung berfoto di dalam pesawat membuat post-crisis reputation Garuda Indonesia juga menurun.

\section{Ucapan Terima Kasih}

Penulis mengucapkan rasa syukur dan terima kasih atas penyelesaian penelitian ini kepada Fakultas Ilmu Komunikasi Universitas Tarumanagara dan para narasumber dan responden yang menjadi populasi penelitian yang sudah bersedia menyediakan waktu serta semua pihak yang terlibat

\section{Daftar Pustaka}

Coombs, W. Timothy \& Holladay, S.J. (2002). Helping crisis managers protect reputational assets: Initial tests of the situational crisis communication theory. Management Communication Quarterly, 16, 165-186.

Krisprimandoyo (2014) Pengaruh Corporate Rebranding Terhadap Loyalitas Penghuni Citraland Surabaya Melalui Brand Associations, Kepuasan Dan Reputasi Perusahaan. Media Mahardhika Vol. 13 No. 2 Januari 2015 
Vol. 4, No. 2, Oktober 2020, Hal 362 - 367

Sugiyono (2017). Metode Penelitian Kuantitatif, Kualitatif, dan R\&D. Bandung: Alfabeta, CV 